\section{DIGITAL COMMONS \\ @ UNIVERSITY OF SOUTH FLORIDA}

\section{ABO: Interactive Journal for Women in the Arts, 1640-1830}

Volume 3

Issue 2 Volume 3.2 (Fall 2013)

Article 1

2013

\title{
Bosom Friends and the Sapphic Breasts of Belinda
}

Ula E. Klein

Stony Brook University, ula.e.klein@gmail.com

Follow this and additional works at: https://digitalcommons.usf.edu/abo

Part of the Dramatic Literature, Criticism and Theory Commons, Educational Methods Commons, Feminist, Gender, and Sexuality Studies Commons, and the Literature in English, British Isles Commons

\section{Recommended Citation}

Klein, Ula E. (2013) "Bosom Friends and the Sapphic Breasts of Belinda," ABO: Interactive Journal for Women in the Arts, 1640-1830: Vol.3: Iss.2, Article 1.

http://dx.doi.org/10.5038/2157-7129.3.2.1

Available at: https://digitalcommons.usf.edu/abo/vol3/iss2/1

This Scholarship is brought to you for free and open access by Digital Commons @ University of South Florida. It has been accepted for inclusion in ABO: Interactive Journal for Women in the Arts, 1640-1830 by an authorized administrator of Digital Commons @ University of South Florida. For more information, please contact digitalcommons@usf.edu. 


\title{
Bosom Friends and the Sapphic Breasts of Belinda
}

\begin{abstract}
This article examines Maria Edgeworth's 1801 novel Belinda in order to argue that the breast at the center of Lady Delacour's narrative signifies not maternal failure but Sapphic feelings and connections. While previous studies of the novel have discussed the wounded breast of Lady Delacour as a punishment for her transgressions or as an emblem of her patriarchal oppression, this article claims that the wounded breast is both a sign of and a means to female same-sex desire and relationships. This article contrasts the wounded, festering breast with the tableau that ends the novel. The tableau, a constructed vision of social expectations at the time, is undermined by Lady Delacour's final couplet that encourages the reader to "find the moral" of the story. The wounded breast and the many ways in which it connects the characters of Lady Delacour, Belinda and Mrs. Freke undermine the heteronormative tableau that ends the novel and complicate the suggestion that the moral of the story is easy to understand. By exploring the ways in which the breast functions to connect these women through its wounding and its cure, I argue that Sapphic possibilities arise throughout the novel. These possibilities suggest the centrality of the female same-sex relationships to the novel over the heterosexual ones that figure in the tableau.
\end{abstract}

\section{Keywords}

Belinda, Maria Edgeworth, eighteenth-century novels, Sapphic, lesbian, breasts

Creative Commons License (c) (i) $\odot$

This work is licensed under a Creative Commons Attribution-No Derivative Works 3.0 License. 
Maria Edgeworth's 1801 novel Belinda is a novel about relations between women, even as it is also a novel about achieving domestic bliss and finding the right mate. One of the central symbols in the novel of both female same-sex relations and imperiled domesticity is the breast of Lady Delacour. Despite the novel's title, it is Lady Delacour who commands much of the attention in Belinda; she is a passionate, spontaneous, and intriguing character, particularly when compared to the rational protagonist Belinda. ${ }^{1}$ She is additionally of interest due to her most mysterious, wounded breast which, according to Lady Delacour herself, is the external mark of her hidden suffering as well as the indiscretions which caused the wound. Read another way, however, Lady Delacour's diseased breast, which she firmly believes is cancerous and slowly but surely killing her, registers her complicated same-sex desires. The central role of Lady Delacour's breast also draws our attention to the other breasts and bosoms in the novel, both corporeal and metaphorical. As we begin to look more closely at the breasts of Belinda, it becomes apparent that the breast is a complicated site of interpretation that connects the women of the novel while also illustrating the importance of their relations to one another as equal to or even as more significant than the male-female relationships. The breast, rather than signifying domestic harmony, comes to symbolize the transgressive nature of female desire, complicating our understanding of the novel's ultimate message.

In Belinda, very little is as it seems. The novel ends with a couplet spoken by Lady Delacour:

Our tale contains a moral, and, no doubt, You all have wit enough to find it out. (Edgeworth 478)

The moral of Belinda is unclear, however, especially given that it is Lady Delacour who speaks it. She recites this couplet after arranging the characters into a tableau, drawing attention to the constructed quality of the narrative and her own role as an actor within it. The constructed tableau, like the wounded breast, casts doubt on our understanding of the novel's moral just as the meaning of the breast is complicated by its sudden return to health. The novel's happy ending is but a theatrical performance, captured in a momentary pause. Through the tableau, the novel reminds the reader of the difficulty of discerning the "proper" reading of a text. Illustrating the distinction between exterior appearance and interior reality, the tableau at the end also gestures towards the novel's overall motif of performance. ${ }^{2}$ In Belinda, pictures of perfection often hide or distort an imperfect, complicated truth as, for example, Lady Delacour's outward appearance as successful society lady is exposed in the novel as a cover-up for her secret ailment. At the same time, the emblem of her unhappiness, her wounded breast, is ultimately revealed as capable of recovery. The wounded breast becomes a central signifier of female desire in the novel, disproving Lady Delacour's earlier assertion that the wounded breast is ruining her life or even killing her. The breast, like the tableau, suggests that imperfections can be preferable to perfection, which can seem dishonest or fabricated. ${ }^{3}$ Thus, the orderly tableau that arranges the characters into normative heterosexual couplings is a performance of social expectations, while the most passionate and permanent relationships are between the female characters, linked as they are through Lady Delacour's breast. ${ }^{4}$

The wound on Lady Delacour's breast initially appears to function as punishment for her inadequacies as a wife and mother. Earlier critics have read her diseased breast as a mark of rebellion that is subdued once Lady Delacour allows the male physicians and surgeons, rather 
than her quack doctor, to examine her. ${ }^{5}$ Other interpretations have suggested that the injury to Lady Delacour's breast is a result of her attempts ". . . to be like a man, from her attempt to transgress the limitations imposed upon her gender" (Ty 164). Conversely, Ruth Perry posits that “. . . Lady Delacour's history could also be read as festering resentment at the colonization of her body, represented synecdochically by the breast that poisons her life" (232). Katherine Montwieler goes further and argues that by revealing that Lady Delacour's breast was never diseased in the first place, the novel shows that Lady Delacour's transgressive behaviors are healthy and positive. ${ }^{6}$ In light of these reconsiderations of the breast, we can no longer read the diseased breast as exclusively the symbol of Lady Delacour's punishment for her earlier rebellious behavior. Instead, the wounded breast at the center of the novel lends itself to a variety of interpretations; Lady Delacour's interpretation is not the only valid one just as the text itself is ambiguous as to its "moral." The breast comes to symbolize not only Lady Delacour's internal battle for happiness, but also her desires for friendship, love, and reciprocal desire, as well as the struggle for female empowerment and the possibilities for strong, emotional and possibly even sexual same-sex bonds. The sexually and emotionally transgressive breast is visible in the novel, engendering Sapphic possibilities in the places where ambiguities exist in the relationships between Lady Delacour, Harriet Freke and Belinda. ${ }^{7}$

The symbolic work of the breast in Belinda complicates much of the scholarship on breasts in the eighteenth century, which has tended to focus on the image of the maternal breast and the increasing insistence over the course of the century on mothers' breast-feeding their own children instead of relying on wet-nurses. Works by Valerie Fildes, Londa Schiebinger, Marina Warner, and Marilyn Yalom form the basis for much of the subsequent discussions on how the meaning of the breast changes during the eighteenth century, becoming less associated with eroticism and sexuality and more attached to the maternal role of women in society. ${ }^{8}$ Schiebinger argues, for example, that Linnaeus coins the term "mammal" in the eighteenth century precisely due to the increasing importance placed on the female breast in the eighteenth century (41). ${ }^{9}$ Yalom explicitly traces this change by arguing that the breast in the Renaissance period was an "erotic breast," while the eighteenth-century breast was connected to political and ideological projects linked to the rise of capitalism and the French Revolution (105). ${ }^{10}$ Perry comes to a similar conclusion; she suggests that it is not just nation-building but the act of colonizing that metaphorically denies women their own breasts and re-appropriates them for patriarchal purposes. ${ }^{11}$ Like Warner and Yalom, Perry suggests that the emphasis on the maternal aspects of womanhood undermined a sexual identity for women in the latter half of the eighteenth century. The function of the breast in Belinda, however, challenges this assumption by making the wounded breast the most powerful appendage in the novel, endowing it with the power to horrify and seduce. While Lady Delacour's breast is represented as horrific, wounded, and in pain, the moment in which she exposes her breast to Belinda re-casts the breast as erotic as it leads the women to partake in both bodily and emotional intimacy. ${ }^{12}$

The breast takes on a transgressive, quasi-erotic quality in Belinda in one of the novel's earliest moments of intimacy between Lady Delacour and Belinda. The moment of revelation becomes a moment of shared emotions between the two women made possible through physical intimacy. The evening after the masquerade, Lady Delacour shows Belinda the truth: that she, the lively, good-humored society lady, is in fact a farce. Underneath the make-up, Lady Delacour is a wreck: "'You are shocked, Belinda,' said she, 'but as yet you have seen nothing-look here_-' 
and baring one half of her bosom, she revealed a hideous spectacle. Belinda sunk back into a chair-lady Delacour flung herself on her knees before her" (32). The scene appears to be about the havoc Lady Delacour's own indiscretions have wrought on her body. She bemoans her past errors to Belinda: “'Am I humbled, am I wretched enough?' cried she, her voice trembling with agony. 'Yes, pity me, for what you have seen; and a thousand times more, for that which you cannot see - my mind is eaten away like my body, by incurable disease - inveterate remorseremorse for a life of folly... "(32). In this scene, the intense emotional confession marks the beginning of a greater intimacy between Lady Delacour and Belinda. There is also a sense of physical intimacy between them as we are asked to imagine one woman showing another woman her breast, ostensibly to reveal "the truth." Lady Delacour exposes her complicated truth at the same time that she exposes an intimate, if imperfect body part, the wounded breast, to Belinda. The wounded breast becomes the path to female intimacy even as it is the result of female indiscretion.

Lady Delacour risks everything to reveal herself to Belinda both bodily and emotionally, and, in this way, the breast becomes the window into her soul. Lady Delacour reveals her breast, which is both erotic and repulsive, in order to expose her true self to Belinda; the revelation of the breast initiates Belinda into the secrets of her friend, engendering intimacies both emotional and bodily. After Lady Delacour discovers her breast to Belinda, she then gets on her knees in front of her, assuming a position that is both one of despair and passion. As the scene continues, "Lady Delacour hid her face on Belinda's lap, and almost stifled by the violence of contending emotions, she at last gave vent to them, and sobbed aloud" (32). Despite all the petticoats and stockings between them, it is undeniable that Lady Delacour is sobbing over Belinda's lap, her breasts pushing against Belinda's legs, with Belinda's own breasts above her head. The position is intimate, emotional, and erotic. Significantly, it is the prelude to the rest of Lady Delacour's "discoveries" of herself to Belinda. First she bares her breast, then she bares herself, and from this moment on Belinda is invited to share in Lady Delacour's secrets as well as her mysterious boudoir. The wounded breast lays the foundation for the increased intimacy, both physical as well as emotional, between the two women. In comparison with the tableau that ends the novel, this scene is chaotic, emotional, and complex; it focuses on embodied relationships rather than the frozen perfection the tableau represents.

The revelation of the imperfect, ruined breast strengthens the friendship between Belinda and Lady Delacour and sets the stage for Lady Delacour's confession of her life and past errors to Belinda. Among her confessions is her failure as a mother, which is also linked to her breasts, as she links her failure in part to her failed attempts at breast-feeding. In this section the novel comments on the new practice of upper- and middle-class women's breast-feeding their own children rather than using a wet-nurse, while also adding another layer of breast-based intimacy to the relationship of Lady Delacour and Belinda. Lady Delacour recounts that

[i]t was the fashion at this time for fine mothers to suckle their own children-so much the worse for the poor brats. . . There was a prodigious rout made about the matter; a vast deal of sentiment and sympathy, and compliments and inquiries; but after the novelty was over, I became heartily sick of the business; and at the end of about three months my poor child was sick too-I don't much like to think of it-it died. (42) 
Disgust with these fashionable people and practices as well as mental fatigue turn into bodily illness and ultimately death for Lady Delacour's child, and her failure to nurse her child successfully appears to be one of her larger faults. She explains that to "put it out to nurse" would have meant being "thought by my friends an unnatural mother" (42). The social pressure to be a perfect mother is evident in Lady Delacour's confession. Her description of breastfeeding as a "fashion" situates the maternal breast as part of a constructed social narrative, a fad, a trend, a social expectation that does not allow for individual imperfections. The novel challenges the view that a mother's own milk is the perfect solution for the child's and the nation's health. Thus, Belinda presents Lady Delacour's wounded breast in a contradictory manner, at first suggesting that Lady Delacour fails as a mother through her failure to breastfeed, only to then question the "fashion" for breast-feeding by explicitly calling it a "fashion." Lady Delacour's inability to nurse her own child can be read as either reiterating her character as a "bad mother," or, using Perry's reading, it can function as a reminder of the pressures on women of the time to fulfill idealized roles. ${ }^{13}$ Lady Delacour's confession exposes her transgressions against approved femininity, as related to the breast, and her desire to control her own body. By revealing the story of her breast to Belinda, Lady Delacour again reveals herself and her inner life to her new bosom friend, while also demonstrating how the struggle against social expectations is in fact a struggle for many women. These struggles and the "void" they create in Lady Delacour are what propel her into the arms of female friends, first Harriet Freke and later Belinda.

Lady Delacour explicitly uses the term "bosom friend" in reference to her former friend Mrs. Freke, suggesting both the centrality of the breast to female same-sex relationships as well as the novel's conflation of body part with emotions (43). Part of the power of Lady Delacour's breast and the bosoms of Belinda is the breast's metaphorical dimension. Although the metaphorical mother's breast that feeds the nation is still represented as belonging to a woman, "breast" has a metaphorical meaning that is gender neutral. Warner points out that historically, "for both sexes [the breast] is the place of the heart, held to be the fountainhead of sincere emotion in both classical culture and our own. . ." and that "in English, the words 'breast' and 'bosom' were not sex-specific either until possibly very recently" (278). The breast/bosom encompasses the possibilities of extreme gender specificity and gender neutrality. This ambiguity links the female characters through the wounded breast as well as through the "bosom friendships" they engender and break. In Belinda, transgressive cross-dressing Harriet Freke, "dying” Lady Delacour, and rational Belinda are affected by the diseased breast as well as the emotional turmoil located in the metaphorical breast. The erotic breast and the emotional breast mingle in the term "bosom friend."

Belinda and Harriet Freke are linked through the breasts of Lady Delacour, Belinda through the revelation of the wounded breast, and Harriet Freke through the very act of its wounding. Both women also function at one time or another as Lady Delacour's "bosom friends." 14 Lady Delacour tells Belinda that she, Belinda, fills an "aching void" in her heart left vacant by Mrs. Freke, a phrase that alludes to the novel's Sapphic love triangle (43). In the same speech, though, she remarks that she searched out Mrs. Freke in order to assuage the void in her heart that could not be filled by marriage or family: "You see I had nothing at home, either in the shape of husband or children, to engage my affections. I believe it was this 'aching void' in my heart 
which made me, after looking abroad some time for a bosom friend, take such a prodigious fancy to Mrs. Freke" (43). Lady Delacour presents the reader with female friendship as an alternative source of emotional fulfillment, while her usage of "bosom friend" reiterates the linguistic slippage that links bosoms, breasts, and same-sex desires. The strength of relationship between the women is evident when Lady Delacour explains to Belinda the pain Mrs. Freke has caused her, equating Mrs. Freke with a past lover, even going so far as to call her a "rake" (47). She tells Belinda that Mrs. Freke "has cost me my peace of mind-my health-my life. She knows it, and she forsakes, betrays, insults, and leaves me to die. I cannot command my temper sufficiently to be coherent when I speak of her-I cannot express in words what I feel" (65). Lady Delacour asks Belinda to recognize the depth and passion of her former relationship with Mrs. Freke. Her relationships with her family have been affected by her abandonment by Mrs. Freke, and without her, Lady Delacour is an "aching void." When Belinda steps in to fill this void, the love-triangle emerges. Significantly, when speaking of Mrs. Luttridge, Lady Delacour explains the power of female relationships by saying, ". . . a woman can always hate a woman more than she can hate a man, unless she has been in love with him" (62). ${ }^{15}$ Lady Delacour's phrasing implies that her feelings for female friends can only be matched by her feelings for men she has loved. She is explicit about her love for Mrs. Freke and her ability to forgive her wily friend almost anything: "Whilst I thought she really loved me, I pardoned her all her faults - All-what a comprehensive word! . . I always thought that she cared for no one but for me. . " (66). Lady Delacour speaks of Harriet Freke like a lover who has jilted her; their relationship is revealed as one that was at once deep and intimate, at least on the part of Lady Delacour, and it is intimately linked to the breast.

Mrs. Freke is indisputably linked to Lady Delacour's breast both through the designation of "bosom friend," as well as through the duel that leads to Lady Delacour's wounded breast. Mrs. Freke is partially responsible for this wound. The rivalry between Mrs. Luttridge and Lady Delacour (which might be read as another Sapphic possibility in the novel) climaxes in a duel between the two women that Mrs. Freke orchestrates. At Mrs. Freke's urging, Lady Delacour challenges Mrs. Luttridge to a duel; when all the women appear at the dueling site, they come dressed in men's clothes (56). After some parley they agree instead to shoot their pistols in the air, leading to Lady Delacour's breast wound: "my pistol was overcharged—when I fired, it recoiled, and I received a blow on my breast, the consequences of which you have seen-or are to see" (57-58). It is Harriet Freke who encourages Lady Delacour to duel, telling her "that the only way left, nowadays, for a woman to distinguish herself, was by spirit," and Lady Delacour claims that she "had prodigious deference for the masculine superiority... of Harriet's understanding" (54). The duel is an initiation ritual for Mrs. Freke, a way to draw her "bosom friend" even closer (43). ${ }^{16}$ According to Lisa L. Moore, "Lady Delacour's wound is, in terms of the novel's sexual economy, a wound to her femininity, the moral consequence of her transgression of gender boundaries in the duel" (96), yet we might also read it as the result of coming face to face with another transgressive boundary in the novel- that of Sapphic possibility.

The Sapphic possibilities of the novel are legible in the places where the text's meaning is ambiguous, where a reader looking queerly at the text can find dissonances in the apparently heteronormative plot. The wounded breast that results from her frolic with Mrs. Freke alienates Lady Delacour from both Mrs. Freke and her husband; yet, it paves the way for a deeper 
intimacy with Belinda. On an emotional level, the revelation of wounded breast and personal history leads Belinda to promise Lady Delacour she will not leave her during her last illness (69). On the bodily level, Belinda is allowed into the mysterious boudoir containing the laudanum used to alleviate the pain in Lady Delacour's breast. Physically, Belinda is brought closer to Lady Delacour through tending to the wounded breast; metaphorically, she becomes the soothing balm for Lady Delacour's aching bosom. When Lady Delacour's carriage is overturned on the way home from the King's birthday celebrations, her ankle is hurt, and she is rushed to her boudoir. She immediately asks for Belinda; she tells the servants to "lay me on this sofa and leave me to Belinda," rejecting the help of her husband in favor of her bosom friend (127). Lord Delacour suggests that perhaps "a lover of lady Delacour's" is concealed in the boudoir, or perhaps "a lover of miss Portman's" (128). His suspicions are ironic given that in the small space of the boudoir, Belinda and Lady Delacour are as intimate as lovers. Once they are alone, Belinda undresses Lady Delacour, another act of intimacy allowed a "bosom friend." The scene may be read as one between devoted friends or devoted lovers; the relationship of Lady Delacour and Belinda is at times strikingly ambiguous, just as the breast occupies an ambiguous space in the novel as it symbolizes transgression and repentance, desire and remorse. Belinda is in the privileged position as intimate, confidant, and companion, and while their relationship is not overtly physical, Sapphic possibilities and Sapphic bosoms haunt the novel.

The Sapphic triangle that forms between Lady Delacour, Belinda and Mrs. Freke is made explicit after Lady Delacour and Belinda "break up" for part of the novel. Belinda is absolved from her promise to Lady Delacour when the latter accuses her of making plans to marry Lord Delacour after her death. Lady Delacour cries out to Belinda, “'Oh Belinda! You! whom I have so loved! so trusted!'” (205). ${ }^{17}$ Their parting is one fraught with accusations, tears, and beseeching, comprising one of the most emotionally intense scenes in the novel, rivaled only by the initial revelation of the breast to Belinda. The rift between the bosom friends allows Harriet Freke to court Belinda, ostensibly to strike a blow to Lady Delacour's ego. At the same time, the rivalry for Belinda triangulates desires between all three women. Mrs. Freke approaches Belinda at the Percivals' home in the country and assumes that there has been an emotional break between her and Lady Delacour. She assures Belinda that "Luttridge and I had such compassion upon you, when we heard you were close prisoner here! I swore to set the distressed damsel free, in spite of all the dragons in Christendom" (225). ${ }^{18}$ Mrs. Freke uses the language of fairy tales, casting herself in the role of Prince to Belinda's "distressed damsel." She assumes that, like the damsels in the stories, Belinda wishes to be freed. She is still loyal to Lady Delacour, however, and resists Mrs. Freke's advances. ${ }^{19}$ The women's bosom friendship survives the impetuous advances of Mrs. Freke, reminding the reader that although Lady Delacour and Belinda are apart, their bosom friendship continues. The reality of this friendship between women, its misunderstandings, rifts, and ultimate forgiveness are not only depicted in more detail than the reconciliation of Lady Delacour to her husband, but they function as the moments of honesty that the final tableau glosses over.

Although her attempts to court Belinda are unsuccessful, Mrs. Freke introduces the revolutionary rhetoric of women's emancipation into the novel. Her arguments reflect the novel's conversation about a woman's right to control her body and her desires. While ridiculous in the mouth of a blow-hard like Mrs. Freke, these radical sentiments echo the freedoms she shared once with Lady Delacour. Mrs. Freke asserts that feminine delicacy is a trap for women: "This delicacy 
enslaves the pretty delicate dears,"” she tells Mr. Percival (229). "'I hate slavery! Vive la liberté!' cried Mrs. Freke, 'I'm a champion for the Rights of Women'” (229). Espousing, perhaps overly simplistically, the sentiments of the French Revolution and those of Mary Wollstonecraft's Vindication of the Rights of Women, Harriet Freke is a disturbing force in the quiet, happy Percival household. Deborah Weiss suggests that "as with most of Freke's declarations, her outbursts here give evidence of the weakness of her ideas and the general impoverishment of her mind" (Weiss 442). I would argue, however, that while her arguments may be unsubstantiated, their existence in the novel is a crucial reminder that other alternatives for women exist, though they may require a revolutionary stance. ${ }^{20}$ Mrs. Freke's emphasis on "delicacy" and how it "enslaves" women is potent given the final result of Clarence Hervey's attempt to cultivate the "perfect" wife. Slavish adherence to social expectations is rejected throughout the novel, even through the carnivalesque character of Mrs. Freke. Her form of courtship, however blundering and unsuccessful, establishes her as a suitor to Belinda and a rival for her heart, while her rhetoric suggests the possibility of radical female camaraderie.

The struggle to claim Belinda further establishes the love triangle between the three women. As with the rare, flowering plant that Lady Delacour steals in order to upstage Mrs. Luttridge, so Belinda functions as well: as a prize that the two women both wish to possess. Lady Delacour herself explicitly sets up Belinda as Mrs. Freke's replacement and opposite when she halffeverishly cries to Belinda, "For what was Harriet Freke in comparison with Belinda Portman? . . .. Oh, Belinda! how entirely have I loved! trusted! admired! adored! respected! revered you!" (183). Moore suggests that "the novel opposes Harriot's [sic] freakish courtship of Belinda with Lady Delacour's ladylike attentions, establishing romantic friendship between 'normal' feminine women as an appropriate relationship within which the women can express intense romantic feeling" (92). Lady Delacour, however, is not a "normal" feminine woman, and even her declarations of love or distrust of Belinda are characterized by a vehemence she does not express for her husband or any other man. Additionally, she and Mrs. Freke have much in common: they both cross-dress and enjoy wearing disguises; they enjoy masquerades and fooling their friends; they are both women with imperiled reputations; they both want Belinda; and ultimately they are both wounded. Lady Delacour's breast is wounded before the novel begins, and Mrs. Freke's legs are wounded before the novel ends. Lady Delacour and Harriet Freke function as doubles whose attributes and motivations are parallel, making it difficult to argue that Lady Delacour is the better match for Belinda. ${ }^{21}$ Lady Delacour shares a "bosom" friendship first with Mrs. Freke and later with Belinda, and the metaphorical and literal meanings of "bosom" slide together in the novel where the breast plays such a significant role. Belinda has access to Lady Delacour's breast and the feelings therein, and she refuses Mrs. Freke the power to penetrate the innermost feelings of her bosom. Ultimately Belinda is the better match for Lady Delacour because she is truly concerned with Lady Delacour's health and well-being.

The intimacy between Lady Delacour and Belinda that originates with the divulging of the diseased breast returns when Lady Delacour's condition worsens. The bosom friend is called back to the sick-bed and the two women are reunited. The evening that Lady Delacour decides to give herself over to the care of Dr. X---, Belinda is at her side; before the surgery, Lady Delacour declares that, "my fortitude shall redeem me in your opinion, Belinda, and in my own" (312). Lady Delacour equates her feelings with Belinda's, as Belinda is her companion, caregiver, and moral compass. The two women might even be said to share the same bosom, as they share in 
the same emotions and expectations. While Lord Delacour and their daughter Helena wait outside the sick room, dreading to hear Lady Delacour's screams of pain, it is Belinda who stands by Lade Delacour's side. It is likewise Belinda who has the pleasure of declaring Lady Delacour healthy to Helena, "her [Belinda's] countenance radiant with joy" (313). A moment later, Belinda is so overcome with joy that "at this moment [she] felt too much to speak," indicating her investment in Lady Delacour's breast (314). Similarly, Lady Delacour's breast can only return to health once her bosom friend is restored to her. Once reunited, the breast is declared to be out of danger, and the bosom friendship can continue.

Mrs. Freke is not missing in the moments when the breast has been declared healthy. Earlier that evening, she is discovered in the garden near Lady Delacour's room, dressed in men's clothes and caught in the gardener's bear trap. Convinced that Lady Delacour is meeting with a male lover, Mrs. Freke comes to catch her in the act. Once she is caught, she learns that the "lover" is only Dr. X---, who has been treating Lady Delacour's breast wound. Her legs are wounded by the bear trap, and she is told "that the beauty of her legs would be spoiled, and that she would never more be able to appear to advantage in man's apparel" (312). Mrs. Freke "grew quite outrageous" at this hint; at the same time, "[t]he dread of being seen by lady Delacour in the deplorable yet ludicrous situation... operated next upon her mind . . " (312). The idea that her former bosom friend will see her wounded, destroyed, and brought low through her own malice strikes "terrour" into Mrs. Freke's heart (312). Lady Delacour, however, views her old friend with compassion: ". . . she never disturbed the lady by her presence. She was too generous to insult a fallen foe" (312). Mrs. Freke is not just a fallen foe, however; at one point she was Lady Delacour's "bosom friend" whose absence left an "aching void." Lady Delacour's decision to give Mrs. Freke the respect the latter frequently denied her not only draws contrasts between their personalities, but it may also allude to the vestiges of tenderness Lady Delacour harbors for her fallen friend. When the breast is declared healthy at the same moment that Mrs. Freke's legs are mangled, the novel suggests that perhaps Mrs. Freke is now punished for the wound she inflicted to Lady Delacour's heart. The breast brings these women together and draws attention to the relationships between these bosom friends and enemies; the breast that finally acquiesces to treatment by hegemonic male authority can still function Sapphically.

Although Lady Delacour is declared healthy once she gives herself up to patriarchal medical authority, after she is healed, she refuses to give up her power completely. She maintains that she has been "won" by kindness, not tamed by it, for "[a] tame lady Delacour would be a sorry animal, not worth looking at. Were she even to become domesticated, she would fare the worse" (314). Thus, Lady Delacour's breast does not signify patriarchally-defined femininity and domesticity; instead, it alludes to her relationships with other women. The breast connects her with Mrs. Freke, Belinda, and even the serving-woman Marriot and her rival Mrs. Luttridge. It is the medium through which Sapphic desire is signified, and it symbolizes Lady Delacour's unwillingness to lose her individuality, even once she is reconciled to her family. The change from her diseased and dying breast to her happy, healthy one is not an about-face, she insists. She is still independent, lively, outspoken and untamed. It is she who arranges the characters into a tableau at the end of the novel, implying that she is the master puppeteer, and it is she who invites the reader to look into the moral of the story, not rational Belinda, perfect Lady Percival, or innocent Helena. The tableau at the end reminds the readers that the novel is a performance within a performance, a construction that can obscure the truth. The imperfections of Lady 
Delacour's breast, after all, reveal the truth of Sapphic desires between Lady Delacour, Belinda and Mrs. Freke. Thus, the tableau, while presenting the final image of the novel with the characters placed in their socially normative pairs, is not devoid of Sapphic resonances, as the tableau itself is clearly defined as a performance.

Lady Delacour is not a woman who has had a complete transformation in the novel; her character consistently resists performing ideal womanhood. We know at the end that she was never dying to begin with, so even her body cannot be said to have transformed. The breast of Lady Delacour was both erotic and Sapphic though perhaps never phallic. Her breast never threatens the men of the novel; it only keeps them at a distance-the distance necessary for Sapphic feelings to blossom. If we consider Lady Delacour's breast as wounded, as containing a wound, the imagery we conjure up is that of concavity and blood, essentially female imagery. Lady Delacour's breast comes to unite the metaphorical feeling organ with her literal female one while remaining intimately tied to the realm of female friendships and Sapphic pleasures. If the moral of the story is so easy to "see," then we must return to a consideration of the realm of the visual. In seeing, we must both look and recognize; Belinda offers us the chance to look and recognize something beyond the heteronormative love story by placing the story of Lady Delacour's breast at the center of the narrative. At the same time, Lady Delacour's breast thematizes the problems of the failure of vision or inadequate vision: only those endowed with the right kind of vision can "find out" the true moral of the story.

The breasts in the novel link the three women together. The violence done to Lady Delacour's breast by the pistol recoil affects both Belinda and Mrs. Freke, the wounded breast being the reason for the bodily disclosure between Belinda and Lady Delacour. The wound itself is a result of Mrs. Freke's own encouragement of Lady Delacour to duel in men's clothes with Mrs. Luttridge. The novel's primary network of affections is between the women, even as Lady Delacour is ultimately reconciled to her husband when she reveals her wound to him, and Belinda is engaged to Clarence Hervey once his own indiscretions are revealed as benign. Belinda's engagement to Clarence and Lady Delacour's reconciliation with her husband merely mean that she and Belinda are free to continue their intimate friendship uninterrupted. Rather than reinforcing a heteronormative love story through the tableau, Lady Delacour arranges everyone in a way that leaves the reader with the sense that these heterosexual couplings are merely for show; the true emotional bonds are all between the women. The Sapphic breasts of Belinda unite the wounded breast, the erotic breast, the maternal breast, as well as the feeling bosom. Through the breast, we are able to discern a network of female affections that constructs emotional connections as well as erotic ones. Ultimately, the breast reveals the transgressive nature of female desires in the novel, which are at their most honest and most complex when they engage the passions of other women. 
Works Cited

Rev. of Belinda by Maria Edgeworth. Monthly Review 37 (1801): 368-74. Print.

Edgeworth, Maria. Belinda. 1801. Ed. Kathryn J. Kirkpatrick. Oxford: Oxford UP, 1999. Print. Oxford's World Classics.

Fildes, Valerie. Breasts, Bottles, and Babies: A History of Infant Feeding. Edinburgh: Edinburgh UP, 1989. Print.

Greenfield, Susan C. “'Abroad and at Home': Sexual Ambiguity, Miscegenation, and Colonial Boundaries in Edgeworth's Belinda." PMLA 112.2 (1997): 214-28. Print.

Kirkpatrick, Kathryn J. Appendix. Belinda. By Maria Edgeworth. 1801. Oxford: Oxford UP, 1999. Print. Oxford's World Classics.

Montwieler, Katherine. "Reading Disease: The Corrupting Performance of Edgeworth's Belinda." Women's Writing 12.3 (2005): 347-68. Print.

Moore, Lisa L. Dangerous Intimacies: Toward a Sapphic History of the British Novel. Durham, NC: Duke UP, 1997. Print.

Perry, Ruth. "Colonizing the Breast: Sexuality and Maternity in Eighteenth-Century England." Part 1: The State, Society, and the Regulation of Sexuality in Modern Europe. Special Issue of Journal of the History of Sexuality 2.2 (1991): 204-34. Print.

Schiebinger, Londa. Nature's Body: Gender in the Making of Modern Science. Boston: Beacon, 1993. Print.

Ty, Eleanor. "Freke in Men's Clothes: Transgression and the Carnivalesque in Edgeworth's Belinda." The Clothes That Wear Us: Essays on Dressing and Transgressing in Eighteenth-Century Culture. Ed. Jessica Munns and Penny Richards. London: Associated UP, 1999. 157-73. Print.

Wahl, Elizabeth. Invisible Relations: Representations of Female Intimacy in the Age of Enlightenment. Stanford: Stanford UP, 1999. Print.

Warner, Marina. Monuments and Maidens: The Allegory of the Female Form. New York: Atheneum, 1985. Print.

Weiss, Deborah. "The Extraordinary Ordinary Belinda: Maria Edgeworth's Female Philosopher.” Eighteenth-Century Fiction 19.4 (2007): 441-61. Print. Yalom, Marilyn. A History of the Breast. New York: Knopf, 1997. Print. 
${ }^{1}$ The earliest reviews of the novel from the Monthly Review in 1801 fault the novel's titular heroine, writing, "The character of the heroine herself creates so little interest, that she appears to have usurped the superior right of Lady Delacour to give the title to the work: for it is to the character and agency of the latter, in our opinion, that the tale owes its principal attraction" (Review of Belinda 368).

2 The preponderance of masquerades and cross-dressing, the disparity between Lady Delacour's exterior performance and her interior unhappiness, as well as the discrepancy between the novel's titular, proper heroine Belinda, and her chaotic and contradictory friend, Lady Delacour, are all illustrative of this motif in the novel.

${ }^{3}$ While my reading does not discuss the story of Clarence Hervey and his ward, Virginia, it is evident in that story as well that perfection in a wife is neither attainable nor desirable. Similarly, the seeming "perfection" of Mr. Vincent as suitor to Belinda is overturned, and Belinda finally accepts Clarence as an imperfect suitor. The one exception to this rule might be Lady Percival, who seems to have no hidden imperfections.

${ }^{4}$ This paper focuses on the triangular relationship of Belinda, Lady Delacour and Harriet Freke. There are other, significant relationships in the novel, though, with echoes of Sapphic desire and/or romantic friendship in them: the relationship of Lady Delacour and her maid Marriot, Belinda and Lady Percival, and Mrs. Freke and Mrs. Luttridge. In many ways, these relationships are also related to Lady Delacour's breast and its wound and are worth further study.

${ }^{5}$ Susan C. Greenfield writes, "The cure constructs her as a domestic woman, whose internal femininity proves her fitness to serve the interior space of the home" (218).

6 "Edgeworth dispels one of sensibility's key tenets, 'unhealthy soul equals an unhealthy body', or she suggests that Lady Delacour's dissentious behavior is salutary" (Montwieler 348).

${ }^{7}$ I have chosen to use the term "Sapphic" in order to denote the possibilities of female same-sex desires, behaviors, and attitudes in the eighteenth century as separate from the twentieth- and twenty-first-century term "lesbian" as it denotes a modern category of sexual orientation. My discussion of Sapphic moments, feelings and possibilities is not one emptied of the erotic; instead, "Sapphic" in this context encompasses sex and the potential for expressions of eros and desire between women, even when physical sex is not described in the text.

${ }^{8}$ See Valerie Fildes, Breasts, Bottles, and Babies: A History of Infant Feeding, Londa Schiebinger, Nature's Body: Gender in the Making of Modern Science, Marina Warner, Monuments and Maidens: The Allegory of the Female Form, and Marilyn Yalom, A History of the Breast.

${ }^{9}$ Schiebinger points out that Linnaeus had a variety of other words he could use to name our particular class of animals, yet he chose to focus on the breast, despite the fact that "the mammae are "functional' in only half of this group of animals (the females)" (41). She focuses on this fact 
as the jumping off point for a discussion of the gender politics inherent in Linnaeus's classification and what it meant for the cultural meaning of the breast.

${ }^{10}$ Yalom argues that "a virulent outcry against wet nursing began to be heard throughout Europe in the mid-eighteenth century from the ranks of moralists, philosophers, physicians, and scientists. Speaking in the name of Nature, they set out to prove that what was natural in the human body was basically good for the body politic" (106).

${ }^{11}$ Perry's argument is that “. . . motherhood was a colonial form-the domestic, familial counterpart to land enclosure at home and imperialism abroad . . . the invention of childhood and the invention of motherhood - can be seen as adaptations of an existing social system to the new political and economic imperatives of an expanding English empire" (206).

${ }^{12}$ Elizabeth Wahl has drawn attention to the indeterminacy of the term "intimacy" in her work on female intimacy in the eighteenth century: "Intimacy reveals what is most cherished and essential to one's identity as an individual, but it is usually marked by a sense of privacy, even secrecy, that transforms the language of intimacy into a kind of code not easily penetrable" (1). Although she acknowledges that the term often encompasses a sexual aspect, in her own work, she separates her discussion of female sexual intimacy from "companionate marriages." By contrast, Lisa L. Moore makes a strong argument for "drawing attention to the sexual reading of intimacy between women that is offered" in eighteenth century novels (6). See Elizabeth Wahl $t$ and Lisa L. Moore.

${ }^{13}$ Lady Delacour herself believes that her failure to breast-feed equals a failure to be a good mother in general, hence her decision to put the care and education of her daughter Helena in the hands of others. The role of the breast in the mother-daughter relationship between Lady Delacour and Helena is yet another female relationship formed through and affected by the breast in the novel.

${ }^{14}$ Moore also notes that for a novel bent upon distinguishing between the "good" Belinda and the "evil" Mrs. Freke, the two women end up functioning very similarly in relation to Lady Delacour: "The rivalry and the comparison set up here between Harriot [sic] and Belinda suggest a troubling equation between two characters who are supposed to represent moral opposites" (93).

${ }^{15}$ Significantly, Mrs. Luttridge is the woman that Mrs. Freke replaces Lady Delacour with. Lady Delacour is betrayed by Mrs. Freke when the latter befriends Mrs. Luttridge, Lady Delacour's sworn enemy, thus exacerbating the wound to her bosom.

${ }^{16}$ Although Lady Delacour's wound can be read as self-inflicted or even the result of fate, it is undeniable that the duel itself is a result of both Lady Delacour's actions as well as Harriet Freke's encouragements. Similarly, the wound has been read as a result of Lady Delacour's appearing in men's clothing; however, the wound to the breast is also symbolic of the way Mrs. Freke metaphorically wounds Lady Delacour's heart/bosom by abandoning her. The multiplicity 
of interpretations of the wound and the breast contribute to making the moral of the novel so difficult, not easy, to see.

${ }^{17}$ While Lady Delacour seems to suggest that she is angry at Belinda for scheming to take away her husband, her accusations also illustrate her pain at the idea that Belinda would prefer someone else over herself.

18 The inclusion of Mrs. Luttridge in her speech suggests that if Belinda left Lady Delacour for the company of Harriet Freke, she would be immediately plunged into yet another Sapphic triangle.

${ }^{19}$ The novel is unclear about Mrs. Freke's motives in this scene. While it is obvious she wishes to have Belinda as a battle prize in the war between herself and Lady Delacour, there is nothing explicitly stating that she is not interested in Belinda in and of herself.

${ }^{20}$ Weiss discusses the influence of Wollstonecraft's work on Belinda more extensively in her article. Her argument, however, focuses much more so on Belinda as a "female philosopher" with Freke as her antithesis.

${ }^{21}$ Significantly, in early drafts of the novel, Lady Delacour was drawn with many of Mrs. Freke's traits; Kathryn J. Kirkpatrick notes that in later drafts, "Edgeworth displaced many of Lady Delacour's offending qualities onto a foil, Harriet Freke" (479). The two characters remain linked through theme as well as plot. 